\title{
Effect of mosaic representation of vegetation in land surface schemes on simulated energy and carbon balances
}

\author{
R. $\mathbf{L i}^{1}$ and V. K. Arora ${ }^{2}$ \\ ${ }^{1}$ Atmospheric Chemistry Division, National Center for Atmospheric Research (NCAR), Boulder, CO 80301, USA \\ ${ }^{2}$ Canadian Centre for Climate Modelling and Analysis, Environment Canada, University of Victoria, Victoria, BC, V8W 2Y2, \\ Canada
}

Correspondence to: V. K. Arora (vivek.arora@ec.gc.ca)

Received: 7 May 2011 - Published in Biogeosciences Discuss.: 22 June 2011

Revised: 28 December 2011 - Accepted: 3 January 2012 - Published: 31 January 2012

\begin{abstract}
Energy and carbon balance implications of representing vegetation using a composite or mosaic approach in a land surface scheme are investigated. In the composite approach the attributes of different plant functional types (PFTs) present in a grid cell are aggregated in some fashion for energy and water balance calculations. The resulting physical environmental conditions (including net radiation, soil moisture and soil temperature) are common to all PFTs and affect their ecosystem processes. In the mosaic approach energy and water balance calculations are performed separately for each PFT tile using its own vegetation attributes, so each PFT "sees" different physical environmental conditions and its carbon balance evolves somewhat differently from that in the composite approach. Simulations are performed at selected boreal, temperate and tropical locations to illustrate the differences caused by using the composite versus mosaic approaches of representing vegetation. These idealized simulations use $50 \%$ fractional coverage for each of the two dominant PFTs in a grid cell. Differences in simulated grid averaged primary energy fluxes at selected sites are generally less than $5 \%$ between the two approaches. Simulated grid-averaged carbon fluxes and pool sizes at these sites can, however, differ by as much as $46 \%$. Simulation results suggest that differences in carbon balance between the two approaches arise primarily through differences in net radiation which directly affects net primary productivity, and thus leaf area index and vegetation biomass.
\end{abstract}

\section{Introduction}

Land surface schemes (LSSs) are integral part of climate models and they simulate the energy and water fluxes at the land-atmosphere boundary (Pitman, 2003). Most land sur- face schemes use specified vegetation attributes (including leaf area index, fractional vegetation coverage and vegetation height) in their energy and water balance calculations. Dynamic global vegetation models (DGVMs) simulate carbon balance of vegetation and soil, and also the structural attributes of vegetation, as a function of climate and atmospheric $\mathrm{CO}_{2}$ concentration (Arora, 2002). When coupled to land surface schemes in climate models, DGVMs provide structural attributes of vegetation as a function of simulated climate so that vegetation becomes a dynamic component of the climate system (Arora, 2002).

There are at least three approaches of representing vegetation within a LSS. The first approach uses grid-averaged structural and physiological attributes of vegetation in energy and water balance calculations (e.g. Verseghy et al., 1993). This approach is referred to as the "composite" approach in which values of albedo, leaf area index (LAI), rooting depth, roughness length and canopy resistance for plant functional types (PFTs) present in a grid cell are aggregated into single values for use by a LSS. Vegetation present in a grid cell is therefore essentially "lumped" from an atmospheric point of view. The result is that all PFTs present in a grid cell "see" the same physical environmental conditions including soil moisture, temperature, and net radiation that are computed with grid-averaged vegetation attributes. The second approach, referred to as the "mosaic" approach, divides a grid cell into "tiles" and energy and water balance calculations are performed separately for each PFT tile (Koster and Suarez, 1992). In a full mosaic approach, the resulting soil moisture and temperature (for individual soil layers) as well as physical variables characterizing the snow layer, if present, for each PFT tile are retained and evolve independently of other tiles. The physical land surface state of each tile in the mosaic approach is the result of interaction of 
its own vegetation attributes with the common meteorological conditions that are seen by all PFTs. Figure 1 schematically illustrates the composite and mosaic approaches. A "mixed" approach, which lies in between the composite and mosaic approaches, uses vegetation attributes of each PFT separately for energy and water balance calculations over each PFT tile, but the resulting soil moisture and temperature are averaged over all tiles at the end of every time step. Koster and Suarez (1992) suggest that the mosaic approach is valid for landscapes characterized by large patches of different PFTs while the composite approach is consistent for landscapes characterized by interspersed PFTs (e.g. mixed deciduous broadleaf and evergreen needleleaf forests). This line of reasoning suggests that the choice between the mosaic and composite approaches depends on the dominant scales of variability in the landscape (Salmun et al., 2009), at least, from an energy and water balance perspective. However, some studies have recommended the mosaic approach for its better results (Klink, 1995; Molod and Salmun, 2002).

While the energy and water balance implications of representing vegetation using the composite and mosaic approaches have been studied (Koster and Suarez, 1992; Klink, 1995; Molod and Salmun, 2002), there have been, to our knowledge, no studies that address the effect of these approaches on the resulting carbon balance. Most current generation earth system models (ESMs) use the composite approach in their large grid cells $\left(\sim 2^{\circ}\right.$ to $5^{\circ}$ resolution) given their computational capacity constraints. However, land grid cells at this resolution inevitably contain different subgrid vegetation patches with very different physical and physiological properties including albedo, stomatal conductance and roughness length. In this paper, we couple the Canadian Terrestrial Ecosystem Model (CTEM) to the latest version of the Canadian Land Surface Scheme (CLASS) that can be run using either the composite or the mosaic approach. Energy and water balance capabilities of CLASS have been evaluated in a number of studies (Verseghy, 2000; Arora 2001; Brown et al., 2006, Marsh et al., 2010) and here we focus on the simulated carbon balance in the coupled CLASS and CTEM models. The objective is to investigate differences in simulated vegetation and soil carbon balance when using the composite and mosaic approaches and gain insight into the physical and ecosystem processes, and their interactions, that lead to these differences. Section 2 of the paper briefly describes the CTEM and CLASS models, and the experimental setup is introduced in Sect. 3. Section 4 presents the modelled results which show how the simulated carbon balance depends on the manner in which vegetation is represented in a LSS. Finally, a summary of results and discussion are presented in Sect. 5.

\section{Coupled terrestrial ecosystem and land surface models}

The configuration described here is comprised of the Canadian Terrestrial Ecosystem Model (CTEM) (Arora, 2003; Arora and Boer, 2005) coupled to the Canadian Land Surface Scheme (CLASS) (version 3.4) (Verseghy, 2009). CLASS was originally developed for use with the Canadian general circulation model (Verseghy, 1991; Verseghy et al., 1993) and for given vegetation attributes it performs energy and water balance calculations at sub-daily time steps (a time step of $30 \mathrm{~min}$ is used here). In the CLASS configuration used here soil temperature and liquid and frozen moisture contents are simulated for three soil layers $(0.10,0.25$ and $3.75 \mathrm{~m}$ deep, with a total soil depth of $4.1 \mathrm{~m}$ ) and the physical state of a single snow layer is prognostically modelled. CLASS models energy and water balance processes for four PFTs: needleleaf trees, broadleaf trees, crops and grasses whose structural attributes including LAI, roughness length, and rooting depth have to be specified if they are present in a grid cell. When coupled to CTEM, these structural vegetation attributes are dynamically simulated by CTEM as a function of environmental conditions. The latest version of CLASS used here (CLASS 3.4) can be run using either the composite or the mosaic approach for a user-specified number of tiles.

CTEM is a process-based terrestrial carbon cycle component of the Canadian Centre for Climate Modelling and Analysis (CCCma) Earth System Models (CanESM1 and CanESM2) (Arora et al., 2009, 2011). CTEM simulates vegetation growth and calculates time-varying carbon storage in three live vegetation pools (leaves, stems, and roots) and two dead carbon pools (litter and soil organic matter) for nine PFTs - needleleaf evergreen and deciduous trees, broadleaf evergreen and cold and dry deciduous trees, and $\mathrm{C}_{3}$ and $\mathrm{C}_{4}$ crops and grasses. Each of CTEM's PFTs falls into the four broader categories considered by CLASS. The photosynthesis and autotrophic and heterotrophic respiration submodules of CTEM, as described in Arora (2003), are used to calculate net primary and net ecosystem productivity. Positive net primary productivity (NPP) is allocated to leaves, stem, and root based on light, root water, and leaf phenological status. Vegetation height (and thus surface roughness length) in CTEM is calculated using the stem biomass for woody PFTs and LAI for herbaceous PFTs (Arora and Boer, 2005). Root distribution and rooting depth are calculated as a dynamic function of root biomass and higher root biomass leads to deeper rooting depths (Arora and Boer, 2003). Leaf phenology in CTEM is modelled on the basis of a carbon-gain approach in which leaf onset is initiated when it is beneficial in carbon terms for a plant to produce leaves. Leaf offset occurs under unfavorable stresses such as short day length, cold temperatures, and dry soil moisture conditions (Arora and Boer, 2005). When coupled to CLASS, CTEM also provides values of canopy conductance used in CLASS' energy and water balance calculations. The current version uses a single-leaf 


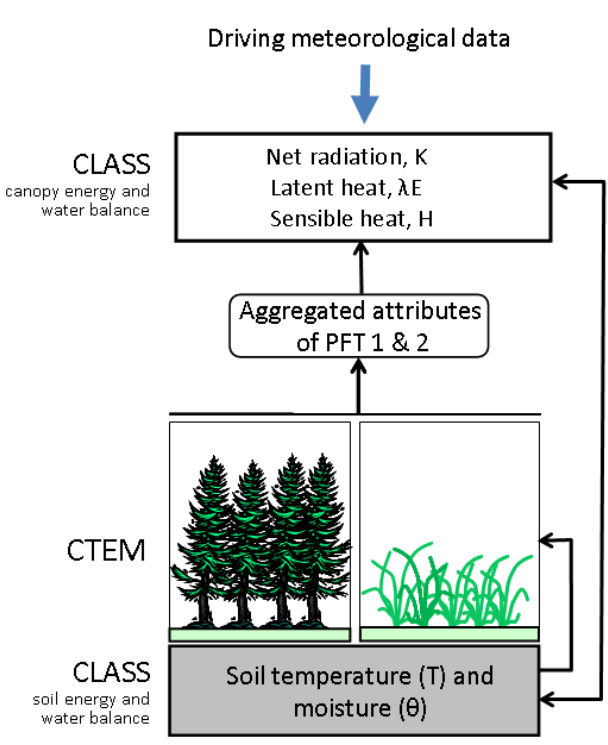

a) The composite approach

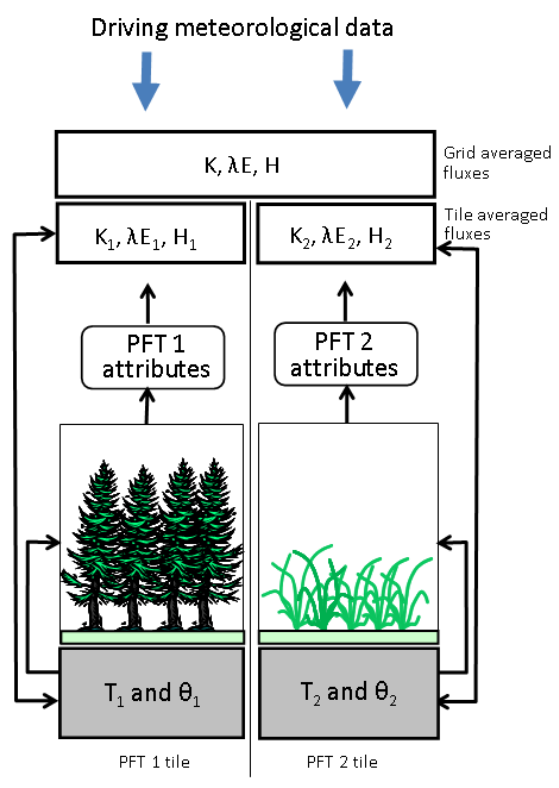

b) The mosaic approach

Fig. 1. The coupling of the Canadian Land Surface Scheme (CLASS) and the Canadian Terrestrial Ecosystem Model (CTEM) in the composite (a) and mosaic (b) approaches.

photosynthesis approach with coupling between photosynthesis and canopy conductance based on vapour pressure deficit (Leuning, 1995). Photosynthesis (and leaf maintenance respiration) calculations are performed at a time step of $30 \mathrm{~min}$ because of the coupling between photosynthesis and canopy conductance, while slower biophysical processes are simulated at a daily time step.

\section{Experimental approach}

Simulations are performed at four locations, which are characterized by different climate and dominant PFTs, using the coupled CTEM and CLASS 3.4 models. The sites include two boreal locations in Manitoba, Canada $\left(53^{\circ} 49^{\prime} \mathrm{N}\right.$, $\left.105^{\circ} 00^{\prime} \mathrm{W}\right)$ and Siberia $\left(61^{\circ} 14^{\prime} \mathrm{N}, 127^{\circ} 30^{\prime} \mathrm{E}\right)$, a temperate location in the eastern United States $\left(42^{\circ} 40^{\prime} \mathrm{N}, 78^{\circ} 45^{\prime} \mathrm{W}\right)$, and a tropical location in Africa $\left(5^{\circ} 34^{\prime} \mathrm{N}, 11^{\circ} 15^{\prime} \mathrm{E}\right)$. Two dominant PFTs, identified with Wang et al. (2006) land cover data (designed for use with CTEM at the global scale), were assigned to a grid cell at each location, with each PFT covering $50 \%$ of the grid cell. Although, of course, more than two PFTs can exist in a given climate model grid cell, and can be handled by CLASS and CTEM, we restrict our analysis to two dominant PFTs for easier interpretation of the results. This simplification does not affect the simulated carbon balance of individual PFTs in the mosaic approach in which each PFT tile interacts with the driving climate data independently of other tiles. In the composite approach, however, the larger the fractional coverage of a PFT the greater is its influence in determining the grid-averaged energy and water balance. Consequently, dominant PFTs in the composite approach affect the carbon balance of sub-dominant PFTs more than the other way around. The choice of each of the two dominant PFTs covering $50 \%$ of the grid cells avoids this confounding effect. In addition, since the vegetation and soil carbon balance is affected by a number of environmental factors and their complex interactions with several ecosystem processes, we found that interpretation of results is difficult when the number of PFTs is greater than two.

Vegetation is represented in CLASS using both the composite and mosaic approaches, which affect the energy and water balances, and the resulting effect on simulated carbon balance is investigated, which is our primary focus. Identical input data for a given location, including meteorological and soil data, are used for simulations performed using the two approaches. The meteorological data are obtained from the global land-surface data set (GOLD) of Dirmeyer and Tan (2001). These data are based on the US National Center for Environmental Prediction (NCEP) reanalysis and have been corrected for several known biases. The data set contains six-hourly values of the required meteorological variables from 1979 to 1999 at $3.75^{\circ}$ resolution. The six-hourly meteorological data are disaggregated into half-hourly values for use by the coupled CLASS 3.4 and CTEM models following Arora and Boer (2005). The fractions of sand and clay for each of three soil layers and the permeable soil depth (which is the depth to bedrock and may be less than the maximum soil depth of $4.10 \mathrm{~m}$ used in CLASS) are obtained 


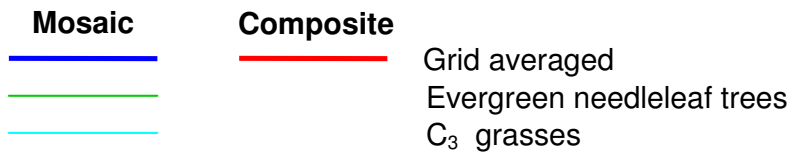

\begin{tabular}{|c|c|c|c|c|}
\hline \multirow{2}{*}{ Energy fluxes } & \multicolumn{2}{|c|}{ Mosaic approach } & Composite approach \\
\cline { 2 - 5 } & Grid averaged & $\begin{array}{c}\text { Evergreen } \\
\text { needleleaf trees }\end{array}$ & C $_{3}$ grasses & Grid-averaged \\
\hline Net radiation $\left(\mathrm{W} \mathrm{m}^{-2}\right)$ & $\mathbf{5 1 . 0}$ & 64.2 & 37.8 & $\mathbf{5 3 . 1}$ \\
\hline $\begin{array}{c}\text { Net radiation over growing } \\
\text { season }\left(\mathrm{W} \mathrm{m}^{-2}\right)\end{array}$ & $\mathbf{8 6 . 7}$ & 102.0 & 71.3 & $\mathbf{9 0 . 0}$ \\
\hline Latent heat flux $\left(\mathrm{W} \mathrm{m}^{-2}\right)$ & $\mathbf{2 1 . 2}$ & 24.7 & 17.7 & $\mathbf{2 3 . 3}$ \\
\hline Sensible heat flux $\left(\mathrm{W} \mathrm{m}^{-2}\right)$ & $\mathbf{2 8 . 5}$ & 37.9 & 19.0 & $\mathbf{2 8 . 4}$ \\
\hline
\end{tabular}

(a) Net Radiation $\left(\mathrm{W} / \mathrm{m}^{2}\right)$

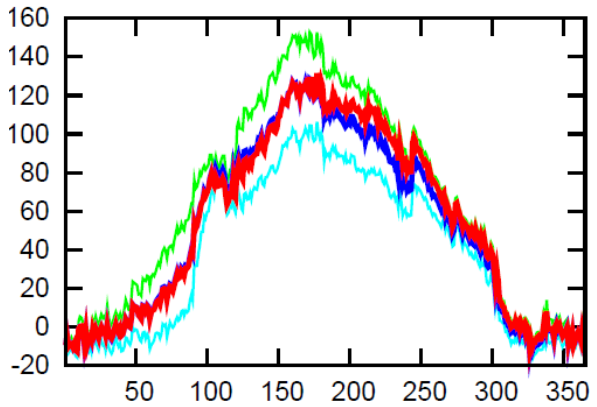

(b) Latent Heat Flux $\left(\mathrm{W} / \mathrm{m}^{2}\right)$

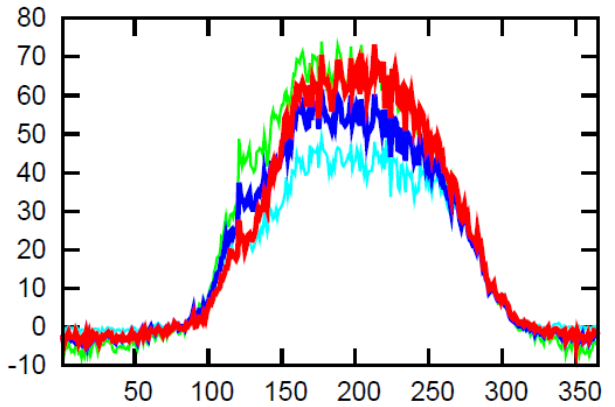

(c) Sensible Heat Flux $\left(\mathrm{W} / \mathrm{m}^{2}\right)$

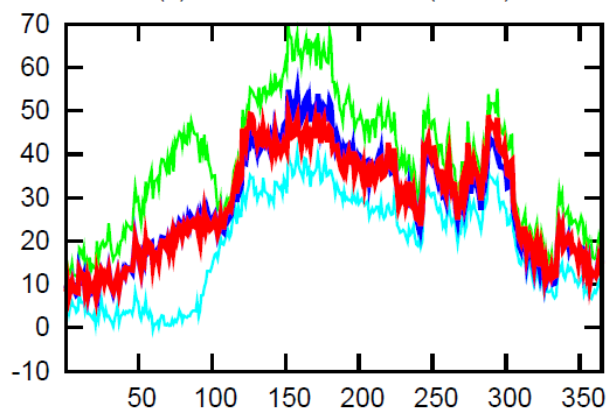

Fig. 2. Simulated daily average values of (a) net radiation, (b) latent heat flux and (c) sensible heat flux for the Manitoba location. The blue and the red lines represent grid-averaged values for the mosaic and composite approaches, respectively. The green and cyan lines represent values for the evergreen needleleaf tree and $\mathrm{C}_{3}$ grass tiles in the mosaic approach, respectively. There are no PFT specific energy fluxes in the composite approach. The table at the top summarizes the average annual values of the fluxes when using the two approaches.

from the standard data set used in CanESM1/2 based on the Zobler (1986) soil data. In the mosaic approach same soil data are used for all tiles in a grid cell.

The $21 \mathrm{yr}$ GOLD meteorological data are used repeatedly at all locations until the simulated carbon pools come into equilibrium using both the composite and mosaic approaches. Simulated primary energy and carbon balance quantities averaged over the last $21 \mathrm{yr}$ are then compared between the two approaches. In the next section, results are first discussed for the two boreal sites followed by the temperate and tropical sites.

\section{Results}

\subsection{The Manitoba and Siberia locations}

Both boreal locations (Manitoba and Siberia) experience cold sub-zero temperatures during winter which leads to pronounced seasonality in temperatures and the majority of the precipitation occurs during summers (see Figs. S1 and S2 in supplementary information). The dominant PFTs are evergreen needleleaf trees and $\mathrm{C}_{3}$ grasses at the Manitoba location, and deciduous needleleaf trees and $\mathrm{C}_{3}$ grasses at the Siberia location. 


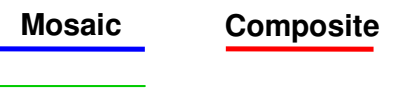

(a) Soil Temperature, top $0.6 \mathrm{~m}\left({ }^{\circ} \mathrm{C}\right)$

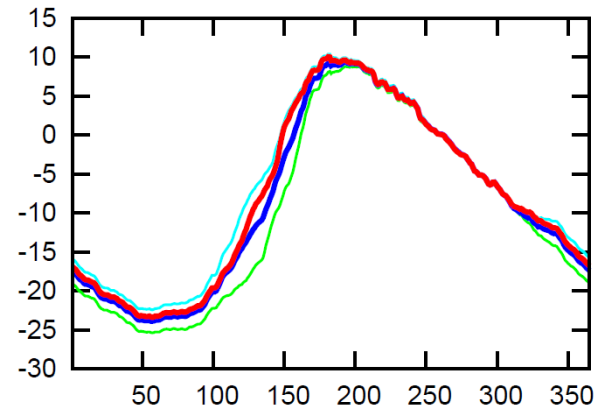

Grid averaged

Deciduous needleleaf trees

$\mathrm{C}_{3}$ grasses

(b) Liquid Soil Moisture, top $0.6 \mathrm{~m}\left(\mathrm{~m}^{3} / \mathrm{m}^{3}\right)$

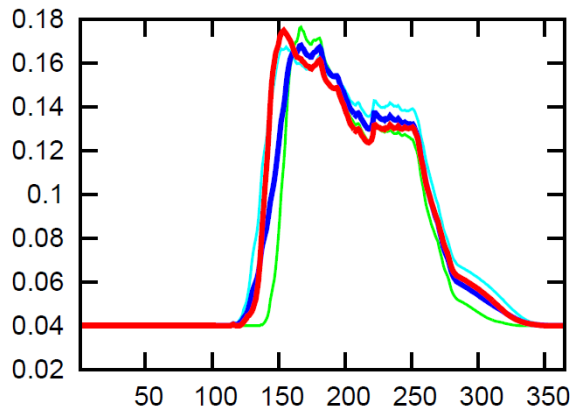

Fig. 3. Simulated daily average values of (a) soil temperature and (b) soil moisture for the Siberia location. The blue and red lines represent grid-averaged values for the mosaic and composite approaches, respectively. The green and cyan lines represent values for the deciduous needleleaf tree and $\mathrm{C}_{3}$ grass mosaic tiles in the mosaic approach, respectively.

\section{Energy fluxes}

Figure 2 shows the simulated daily averaged values of net radiation, latent heat and sensible heat fluxes at the Manitoba location. Plots are shown for individual PFT values in the mosaic approach as well as grid-averaged values for both approaches. In the composite approach PFTs present in a grid cell experience the same energy fluxes, which are computed using grid-averaged vegetation attributes, so there are no PFT specific energy fluxes in the composite approach. The daily average net radiation in Fig. 2a shows a similar seasonal pattern for individual PFT tiles (green and cyan lines) in the mosaic approach as well as grid-averaged quantities obtained using the composite (red line) and mosaic (blue line) approaches since the driving downwelling radiation is the same for all cases. The differences in grid-averaged net radiation between the composite (red line) and mosaic (blue line) approaches are small. However, there is a significant difference between the net radiation flux for the individual PFT tiles in the mosaic approach and more so over the growing season (about day 100 to 310 at the Manitoba location based on leaf onset and offset of $\mathrm{C}_{3}$ grasses, Fig. 4b). In Fig. 2a, net radiation values (positive downward) are higher for the evergreen needleleaf tree tile (green line) than for the $\mathrm{C}_{3}$ grass tile (cyan line) because of two reasons. First, the darker needleleaf trees (albedo of 0.11) absorb more radiation than the brighter $\mathrm{C}_{3}$ grasses (albedo of 0.18). Second, the simulated surface temperature over the $\mathrm{C}_{3}$ grass tile is up to $4{ }^{\circ} \mathrm{C}$ higher during the summer season (not shown) which increases the outgoing longwave radiation. The higher temperature over the $\mathrm{C}_{3}$ grass tile is the result of its lower canopy heat capacity (because of lower vegetation biomass) as well as lower LAI (which causes reduced shading) compared to the needleleaf evergreen tree tile (Fig. 4b). In comparison, both PFTs in the composite approach receive the same net radiation which is calculated using the grid-averaged albedo and surface temperature. The sharp increase in net radiation for $\mathrm{C}_{3}$ grasses around day $100(\sim 10$ April) in the mosaic approach is the result of leaf onset for grasses (as shown in Fig. 4b) while the increase in net radiation for evergreen needleleaf trees is more gradual and is primarily the result of increase in downwelling radiation. Figures $2 b$ and $c$ show that for the Manitoba location the composite approach yields higher grid-averaged latent heat flux (positive upward), especially during summer (the red line is higher than the blue line), but similar sensible heat flux (positive upward) compared to the mosaic approach.

Qualitatively similar results are obtained for the Siberia location where the net radiation values are higher for the darker deciduous needleleaf trees than for the brighter $\mathrm{C}_{3}$ grasses (Table 1) in response to differences in albedo and temperature (warmer temperatures over the $\mathrm{C}_{3}$ grass tile as seen in Fig. 3a, which shows soil temperatures for the top $0.6 \mathrm{~m}$ at the Siberia location). The difference between the two sites is that while the needleleaf trees at the Manitoba location have evergreen phenology they have deciduous phenology at the Siberia location. Compared to the composite approach, the mosaic approach yields higher latent and sensible heat fluxes for needleleaf trees at both locations and lower values for $\mathrm{C}_{3}$ grasses, primarily in response to the differences in net radiation. The implication of differences in net radiation flux is that in the composite approach the needleleaf trees receive less and $\mathrm{C}_{3}$ grasses receive more radiation than in the mosaic approach, at both locations. Since radiation is an important driver for vegetation growth these differences in net radiation have significant impacts on the carbon balance, as discussed later. 


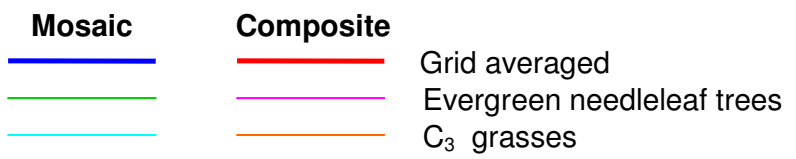

\begin{tabular}{|c|c|c|c|c|c|c|}
\hline \multirow{2}{*}{ Carbon quantities } & \multicolumn{3}{|c|}{ Mosaic approach } & \multicolumn{3}{c|}{ Composite approach } \\
\cline { 2 - 7 } & $\begin{array}{c}\text { Grid- } \\
\text { averaged }\end{array}$ & $\begin{array}{c}\text { Evergreen } \\
\text { needleleaf trees }\end{array}$ & C $_{3}$ grasses & $\begin{array}{c}\text { Grid- } \\
\text { averaged }\end{array}$ & $\begin{array}{c}\text { Evergreen } \\
\text { needleleaf trees }\end{array}$ & $\mathrm{C}_{3}$ grasses \\
\hline NPP $\left(\mathrm{g} \mathrm{C} \mathrm{m}^{-2} \mathrm{yr}^{-1}\right)$ & $\mathbf{2 3 4 . 1}$ & 355.0 & 113.3 & $\mathbf{3 1 6 . 8}$ & 292.5 & 341.1 \\
\hline Max. LAI ( m $\left.{ }^{-2}\right)$ & $\mathbf{1 . 8}$ & 2.8 & 0.9 & $\mathbf{2 . 3}$ & 2.4 & 2.2 \\
\hline $\begin{array}{c}\text { Soil carbon mass } \\
\left(\mathrm{Kg} \mathrm{C} \mathrm{m}^{-2}\right)\end{array}$ & $\mathbf{6 . 1}$ & 7.0 & 5.2 & $\mathbf{8 . 9}$ & 5.5 & 12.2 \\
\hline $\begin{array}{c}\text { Vegetation biomass } \\
\left(\mathrm{Kg} \mathrm{C} \mathrm{m}^{-2}\right)\end{array}$ & $\mathbf{2 . 5}$ & 4.9 & 0.2 & $\mathbf{2 . 1}$ & 3.7 & 0.6 \\
\hline
\end{tabular}

(a) NPP [g $\mathrm{C} /\left(\mathrm{m}^{2}\right.$ day $\left.)\right]$

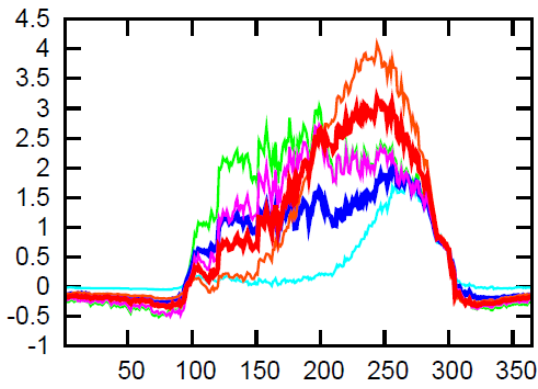

(b) $\mathrm{LAl}\left(\mathrm{m}^{2} / \mathrm{m}^{2}\right)$

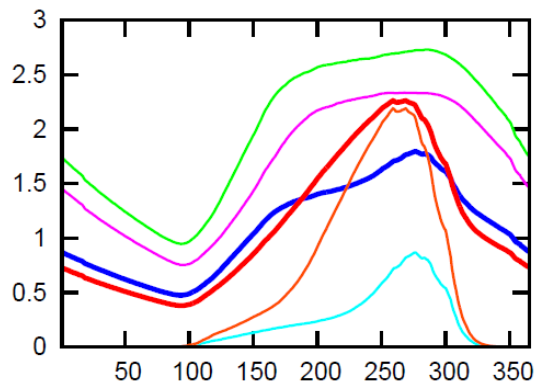

Fig. 4. Simulated daily averaged values of (a) NPP and (b) LAI for the Manitoba location for individual PFTs and grid-averaged values when using the two approaches. The table at the top summarizes the average annual values of NPP, vegetation biomass, soil carbon mass, and annual maximum values of LAI when using the two approaches.

Table 1. Average annual values of primary energy fluxes at the Siberia location when using the composite and mosaic approaches.

\begin{tabular}{lcccc}
\hline \multirow{2}{*}{ Energy fluxes } & \multicolumn{2}{c}{ Mosaic approach } & \multicolumn{2}{c}{ Composite approach } \\
\cline { 2 - 5 } & Grid averaged & Deciduous needleleaf trees & C $_{3}$ grasses & Grid-averaged \\
\hline Net radiation $\left(\mathrm{W} \mathrm{m}^{-2}\right)$ & $\mathbf{4 1 . 8}$ & 48.7 & 35.0 & $\mathbf{4 4 . 3}$ \\
Net radiation over growing season $\left(\mathrm{W} \mathrm{m}^{-2}\right)$ & $\mathbf{1 0 0 . 7}$ & 114.1 & 83.5 & $\mathbf{1 0 5 . 9}$ \\
Latent heat flux $\left(\mathrm{W} \mathrm{m}^{-2}\right)$ & $\mathbf{1 3 . 3}$ & 13.5 & 13.1 & $\mathbf{1 3 . 2}$ \\
Sensible heat flux $\left(\mathrm{W} \mathrm{m}^{-2}\right)$ & $\mathbf{2 6 . 9}$ & 33.5 & 20.3 & $\mathbf{2 9 . 3}$ \\
\hline
\end{tabular}

The differences in energy fluxes lead to differences in soil temperature and moisture between individual PFT tiles in the mosaic approach, as well as when compared to values in the composite approach. Figure 3 shows the soil temperature and moisture at the Siberia location for the top $60 \mathrm{~cm}$ soil layer, where majority of simulated roots are located for deciduous needleleaf trees $(\sim 82 \%)$ and $\mathrm{C}_{3}$ grasses $(\sim 99 \%)$. As expected, at this high-latitude northerly location liquid soil moisture drops to its minimum value during winter when almost all soil moisture is frozen. Grid-averaged liquid soil moisture content and soil temperatures are similar when using the composite and mosaic approaches but differences exist between the individual PFT tiles in the mosaic approach.
In CLASS, the radiation reaching the ground is an exponential function of LAI. The higher the LAI, the more radiation is intercepted by the canopy leaves and the less reaches the ground. In addition, for woody PFTs, radiation is also intercepted by stems based on a stem area index (SAI). At both boreal locations, $\mathrm{C}_{3}$ grasses have lower simulated LAI than needleaf trees (Figs. 4b and 5b). As a consequence compared to the composite approach which uses grid-averaged LAI, the $\mathrm{C}_{3}$ grasses tile receives relatively more radiation at the ground surface in the mosaic approach. The amount of radiation reaching the ground surface, of course, also depends on net radiation at the top of the canopy. In Fig. 3 for the Siberia location, the net result is that the soil temperature 
and moisture of the $\mathrm{C}_{3}$ grass (needleleaf deciduous tree) tile starts to increase earlier (later) and are higher (lower) because of more (less) radiation reaching the ground surface in the mosaic approach than the grid-averaged values in the composite approach. Qualitatively similar results are obtained at the Manitoba location (not shown).

\section{Carbon fluxes and pools}

Figure 4 compares the daily averaged values of primary carbon quantities (NPP, LAI, soil carbon mass and vegetation biomass) from simulations using the composite and mosaic approaches for the Manitoba location. Compared to Fig. 2, there are two additional lines in each panel, in magenta and orange colors, which represent PFT-specific carbon quantities in the composite approach. While grid-averaged vegetation attributes are used for energy and water balance calculations in the composite approach by CLASS, CTEM still calculates all terrestrial ecosystem processes separately for the PFTs present in a grid cell albeit using same physical environmental conditions, as illustrated in Fig. 1.

Figure 4 shows large differences between carbon quantities when simulated using the composite and mosaic approaches for the Manitoba location. All quantities are higher for $\mathrm{C}_{3}$ grasses and lower for evergreen needleleaf trees in the composite approach compared to the mosaic approach. In Fig. 4a, NPP of evergreen needleleaf trees is lower in the composite approach (magenta line below the green line) because evergreen needleleaf trees receive lower net radiation than in the mosaic approach, as mentioned earlier (see Fig. 2a). In contrast, the productivity of $\mathrm{C}_{3}$ grasses is higher in the composite approach (orange line above the cyan line) than in the mosaic approach because they receive higher net radiation in the composite approach. These differences in NPP lead to differences in simulated LAI, soil carbon mass and vegetation biomass (summarized in the table above the figure). In Fig. 4b, CTEM simulates the seasonality of leaf area indices for both PFTs realistically at the Manitoba location, but some limitations remain. Evergreen needleleaf trees retain leaves throughout the year but the simulated seasonal variability is likely too large. $\mathrm{C}_{3}$ grasses, as expected, are active during summer and dormant during winter but the LAI peaks towards the end of the growing season and not during the middle of the growing season as is generally observed.

Figure $4 \mathrm{~b}$ shows that absolute values of LAI are different between the two approaches with evergreen needleleaf trees exhibiting lower LAI and the $\mathrm{C}_{3}$ grasses showing more than doubling of maximum annual LAI in the composite approach compared to the mosaic approach. The increased LAI for $\mathrm{C}_{3}$ grasses in the composite approach is the result of higher NPP due to higher net radiation received by $\mathrm{C}_{3}$ grasses. The table in Fig. 4 shows that the use of the composite approach at the Manitoba location significantly increases soil carbon mass for $\mathrm{C}_{3}$ grasses by $\sim 135 \%$. In contrast, the simulated soil carbon mass for needleleaf trees is slightly lower in the composite approach than in the mosaic approach. While all other grid-averaged carbon quantities are higher in the composite approach it yields slightly lower grid averaged vegetation biomass than in the mosaic approach (Fig. 4). This is because the decrease in the vegetation biomass for evergreen needleleaf trees in the composite approach, due to lower net radiation, is not compensated by increase in the vegetation biomass of $\mathrm{C}_{3}$ grasses, which receive higher radiation in the composite approach. Grasses do not include the woody stem component and thus for the same NPP they yield lower vegetation biomass but higher soil carbon mass because of their lower soil decomposition rates compared to woody PFTs (Guo and Gifford, 2002; Jackson et al., 2002; Arora and Boer, 2010). Overall at the Manitoba location, net radiation is the primary driver of differences in the carbon balance between the two approaches. Grid-averaged NPP and soil carbon mass are up to $46 \%$ higher, but grid-averaged vegetation biomass is slightly lower, in the composite approach compared to the mosaic approach.

Figure 5 compares the daily averaged values of primary carbon quantities for the Siberia location. The growing season is short for both $\mathrm{C}_{3}$ grasses and deciduous needleleaf trees at this high-latitude location. Both PFTs start to grow in late spring (indicated by positive NPP and leaf onset in Fig. 5a and b, respectively) when the favourable weather arrives and become dormant in early fall when physical environmental conditions become unfavourable. NPP, LAI and vegetation biomass (Table in Fig. 5) are all higher for both deciduous needleleaf trees and $\mathrm{C}_{3}$ grasses in the composite approach compared to the mosaic approach. This behaviour is in contrast to the Manitoba location, where these carbon quantities were smaller for the evergreen needleleaf trees and larger for $\mathrm{C}_{3}$ grasses in the composite compared to the mosaic approach, primarily in response to the lower and higher net radiation these PFTs received. For the Siberia location, NPP, LAI and vegetation biomass are higher for $\mathrm{C}_{3}$ grasses in the composite approach compared to the mosaic approach because the higher net radiation (Table 1) more than compensates for the slightly lower soil moisture (Fig. 3b). The NPP of deciduous needleleaf trees is slightly higher in the composite approach despite lower net radiation (Table 1), whose effect is overcome by an early leaf onset ( $\sim 9$ days) (Fig. 5b) associated with early availability of liquid soil moisture (Fig. 3b), compared to the mosaic approach. In CTEM, leaf onset is initiated when net photosynthesis for leaves (photosynthesis minus leaf respiration) remains positive for seven consecutive days and PFT-specific environmental constraints are also relieved (Arora and Boer, 2005). Early availability of liquid soil moisture implies that the former condition is met earlier in the composite approach leading to higher NPP, LAI and vegetation biomass.

Values of soil carbon, which depend on NPP as well as respiration from the soil carbon pool, behave somewhat differently than vegetation biomass. Higher values of NPP increase soil carbon and higher values of temperature and 


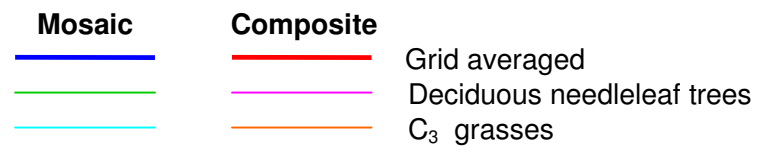

\begin{tabular}{|c|c|c|c|c|c|c|}
\hline \multirow{2}{*}{ Carbon quantities } & \multicolumn{3}{|c|}{ Mosaic approach } & \multicolumn{3}{c|}{ Composite approach } \\
\cline { 2 - 8 } & $\begin{array}{c}\text { Grid- } \\
\text { averaged }\end{array}$ & $\begin{array}{c}\text { Deciduous } \\
\text { needleleaf trees }\end{array}$ & $\mathrm{C}_{3}$ grasses & $\begin{array}{c}\text { Grid- } \\
\text { averaged }\end{array}$ & $\begin{array}{c}\text { Deciduous } \\
\text { needleleaf trees }\end{array}$ & $\mathrm{C}_{3}$ grasses \\
\hline NPP $\left(\mathrm{g} \mathrm{C} \mathrm{m}^{-2} \mathrm{yr}^{-1}\right)$ & $\mathbf{1 3 8 . 0}$ & 152.8 & 123.3 & $\mathbf{1 8 6 . 2}$ & 195.7 & 176.7 \\
\hline Max. LAI ( m $\left.\mathrm{m}^{-2}\right)$ & $\mathbf{1 . 2}$ & 1.8 & 0.6 & $\mathbf{1 . 5}$ & 2.2 & 0.9 \\
\hline Soil carbon mass $\left(\mathrm{Kg} \mathrm{C} \mathrm{m}^{-2}\right)$ & $\mathbf{1 4 . 9}$ & 17.6 & 12.2 & $\mathbf{1 6 . 1}$ & 16.2 & 16.0 \\
\hline Vegetation biomass $\left(\mathrm{Kg} \mathrm{C} \mathrm{m}^{-2}\right)$ & $\mathbf{1 . 3}$ & 2.4 & 0.2 & $\mathbf{1 . 7}$ & 3.1 & 0.3 \\
\hline
\end{tabular}

(a) NPP $\left[\mathrm{g} \mathrm{C} /\left(\mathrm{m}^{2}\right.\right.$ day $\left.)\right]$

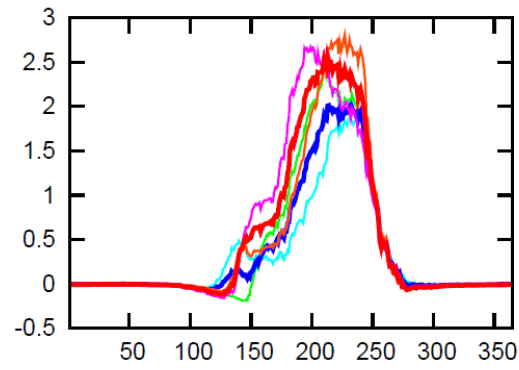

(b) $\mathrm{LAI}\left(\mathrm{m}^{2} / \mathrm{m}^{2}\right)$

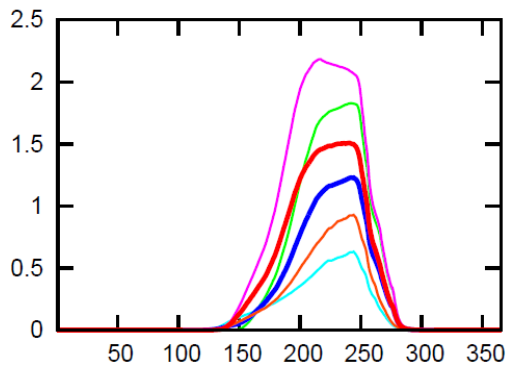

Fig. 5. Simulated daily averaged values of (a) NPP and (b) LAI for the Siberia location for individual PFTs and grid-averaged values when using the two approaches. The table at the top summarizes the average annual values of NPP, vegetation biomass, soil carbon mass, and annual maximum values of LAI when using the two approaches.

favourable moisture conditions, which increase respiration, decrease soil carbon. Soil carbon values for $\mathrm{C}_{3}$ grasses are higher in the composite approach compared to the mosaic approach (Table in Fig. 5), in response to increase in NPP (Fig. 5a) as well as lower soil temperature (Fig. 3a). Soil carbon values for deciduous needleleaf trees are lower in the composite compared to the mosaic approach despite higher NPP (Fig. 5a) because of the higher soil temperature (Fig. 3a) and moisture (Fig. 3b) which increase soil respiration and consequently decrease the equilibrium value of soil carbon.

Unlike the Manitoba location where the differences in net radiation are the primary driver of differences in carbon balance, at the Siberia location the differences in soil moisture (which initiates early leaf onset in the composite approach for the deciduous needleleaf trees) also play an important role. Differences in soil moisture between the two approaches become important at the Siberia location because of the deciduous phenology of needleleaf trees at this location compared to their evergreen phenology at the Manitoba location. Overall, at the Siberia location, differences in net radiation, soil moisture and soil temperature and their interactions with various ecosystem processes between the two approaches all contribute to differences in the simulated carbon balance between the two approaches yielding $35 \%$ higher NPP, $8 \%$ higher soil carbon mass and $31 \%$ higher vegetation biomass in the composite approach.

\subsection{The Eastern United States location}

The Eastern United States location shows less pronounced seasonality in temperature compared to the two boreal locations and precipitation is more or less uniformly distributed over the year (see Fig. S3 in supplementary information). The two dominant PFTs at this location are broadleaf cold deciduous trees and $\mathrm{C}_{3}$ crops. The broadleaf cold deciduous trees with their lower albedo (albedo of 0.17) are characteristically darker than the $\mathrm{C}_{3}$ crops (albedo of 0.20). The difference in the albedos of cold deciduous broadleaf trees and $\mathrm{C}_{3}$ crops at this location is smaller than the difference in albedos of needleleaf trees and $\mathrm{C}_{3}$ grasses at the Manitoba and Siberia locations.

Table 2 compares the energy fluxes at this location obtained using the two approaches. The differences in grid averaged net radiation, latent and sensible heat fluxes between the two approaches are small and around 3-5\%. The net radiation fluxes for the individual PFTs, however, differ considerably in the mosaic approach with higher differences over the growing season (determined using seasonality of LAI) because of the differences in their albedos. The brighter $\mathrm{C}_{3}$ crops receive less and the darker broadleaf trees receive more radiation in the mosaic approach than in the composite approach (which uses grid-averaged albedo). 
Table 2. Average annual values of primary energy fluxes at the Eastern United States location when using the composite and mosaic approaches.

\begin{tabular}{lcccc}
\hline \multirow{2}{*}{ Energy fluxes } & & Mosaic approach & \multicolumn{2}{c}{ Composite approach } \\
\cline { 2 - 5 } & Grid averaged & Cold deciduous broadleaf trees & C $_{3}$ crops & Grid-averaged \\
\hline Net radiation $\left(\mathrm{W} \mathrm{m}^{-2}\right)$ & $\mathbf{5 9 . 3}$ & 66.1 & 53.3 & $\mathbf{6 1 . 8}$ \\
Net radiation over growing season $\left(\mathrm{W} \mathrm{m}^{-2}\right)$ & $\mathbf{9 3 . 5}$ & 101.0 & 86.1 & $\mathbf{9 7 . 9}$ \\
Latent heat flux $\left(\mathrm{W} \mathrm{m}^{-2}\right)$ & $\mathbf{3 4 . 5}$ & 37.9 & 31.6 & $\mathbf{3 6 . 3}$ \\
Sensible heat flux $\left(\mathrm{W} \mathrm{m}^{-2}\right)$ & $\mathbf{2 3 . 2}$ & 26.5 & 20.2 & $\mathbf{2 3 . 9}$ \\
\hline
\end{tabular}

$\begin{array}{lll}\text { Mosaic } & \text { Composite } \\ \square & \begin{array}{l}\text { Grid averaged } \\ \text { Cold deciduous broadleaf trees } \\ \end{array} & \mathrm{C}_{3} \text { crops }\end{array}$

\begin{tabular}{|c|c|c|c|c|c|c|}
\hline \multirow[b]{2}{*}{ Carbon quantities } & \multicolumn{3}{|c|}{ Mosaic approach } & \multicolumn{3}{|c|}{ Composite approach } \\
\hline & $\begin{array}{c}\text { Grid- } \\
\text { averaged }\end{array}$ & $\begin{array}{l}\text { Cold deciduous } \\
\text { broadleaf trees }\end{array}$ & $\mathrm{C}_{3}$ crops & $\begin{array}{c}\text { Grid- } \\
\text { averaged }\end{array}$ & $\begin{array}{l}\text { Cold deciduous } \\
\text { broadleaf trees }\end{array}$ & $\mathrm{C}_{3}$ crops \\
\hline $\mathrm{NPP}\left(\mathrm{g} \mathrm{C} \mathrm{m}^{-2} \mathrm{yr}^{-1}\right)$ & 481.2 & 695.3 & 292.8 & 679.0 & 642.7 & 712.9 \\
\hline $\operatorname{Max} . \mathrm{LAI}\left(\mathrm{m}^{2} \mathrm{~m}^{-2}\right)$ & 2.4 & 3.9 & 1.3 & 3.3 & 3.8 & 2.8 \\
\hline Soil carbon mass $\left(\mathrm{Kg} \mathrm{C} \mathrm{m}^{-2}\right)$ & 7.4 & 12.5 & 3.0 & 9.3 & 11.3 & 7.6 \\
\hline Vegetation biomass $\left(\mathrm{Kg} \mathrm{C} \mathrm{m}^{-2}\right)$ & 3.6 & 7.6 & 0.05 & 3.5 & 7.3 & 0.13 \\
\hline
\end{tabular}

(a) NPP $\left[\mathrm{g} \mathrm{C} /\left(\mathrm{m}^{2}\right.\right.$ day $\left.)\right]$

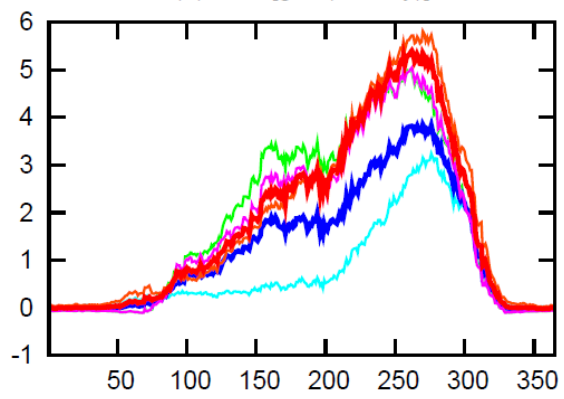

(b) LAI $\left(\mathrm{m}^{2} / \mathrm{m}^{2}\right)$

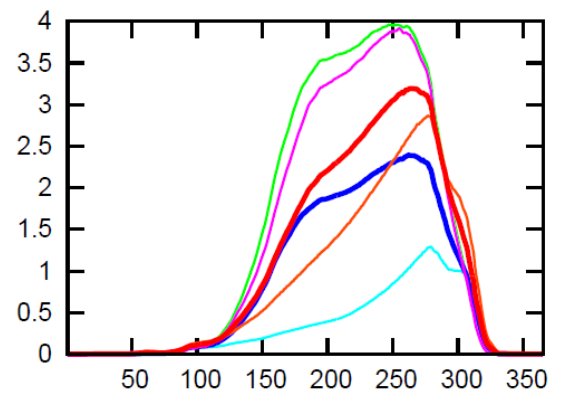

Fig. 6. Simulated daily averaged values of (a) NPP and (b) LAI for the Eastern US location for individual PFTs and grid-averaged values when using the two approaches. The table at the top summarizes the average annual values of NPP, vegetation biomass, soil carbon mass, and annual maximum values of LAI when using the two approaches.

Similar to the Manitoba location, the differences in net radiation are the primary driver of differences in carbon balance between the two approaches (Fig. 6). The NPP and LAI of $\mathrm{C}_{3}$ crops more than doubles in the composite approach resulting in $41 \%$ higher grid-averaged NPP and $26 \%$ higher grid-averaged soil carbon. The vegetation biomass of $\mathrm{C}_{3}$ crops remains small in both approaches because crops are harvested at the end of their growing season and therefore do not contribute much to the grid averaged vegetation biomass (see table at the top in Fig. 6). The NPP and LAI of cold deciduous broadleaf trees reduces in the composite approach because of less radiation they receive resulting in their lower vegetation and soil carbon mass. The changes in carbon quantities are larger for $\mathrm{C}_{3}$ crops than for cold deciduous broadleaf trees because of their larger percentage difference in net radiation between the two approaches. Overall, at this location the use of the composite approach leads to higher grid-averaged NPP, LAI and soil carbon mass.

\subsection{The Africa location}

The daily average temperature at the location in Africa has the least pronounced seasonal cycle of all locations (see Fig. S4 in supplementary information). This tropical site experiences an approximately 60-70 day long dry season with most precipitation falling from late February to early November. 


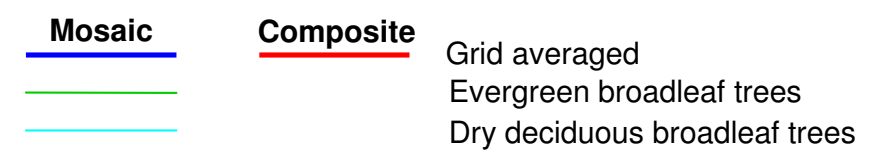

(a) Soil Temperature, top $1 \mathrm{~m}\left({ }^{\circ} \mathrm{C}\right)$

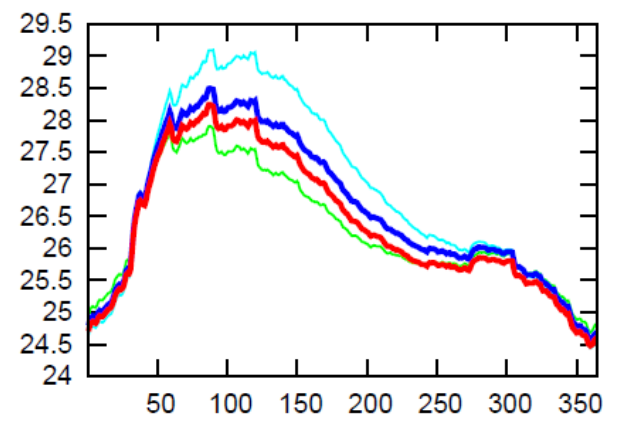

(b) Liquid Soil Moisture, top $1 \mathrm{~m}\left(\mathrm{~m}^{3} / \mathrm{m}^{3}\right)$

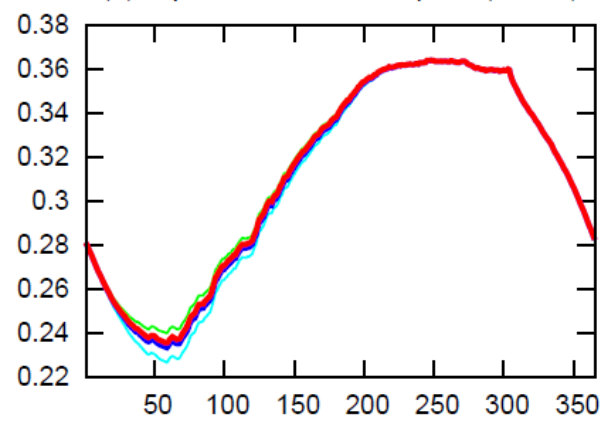

Fig. 7. Simulated daily average values of (a) soil temperature and (b) soil moisture for the Africa location. The blue and red lines represent grid-averaged values for the mosaic and composite approaches, respectively. The green and cyan lines represent values for the evergreen broadleaf tree and dry deciduous broadleaf tree mosaic tiles in the mosaic approach, respectively.

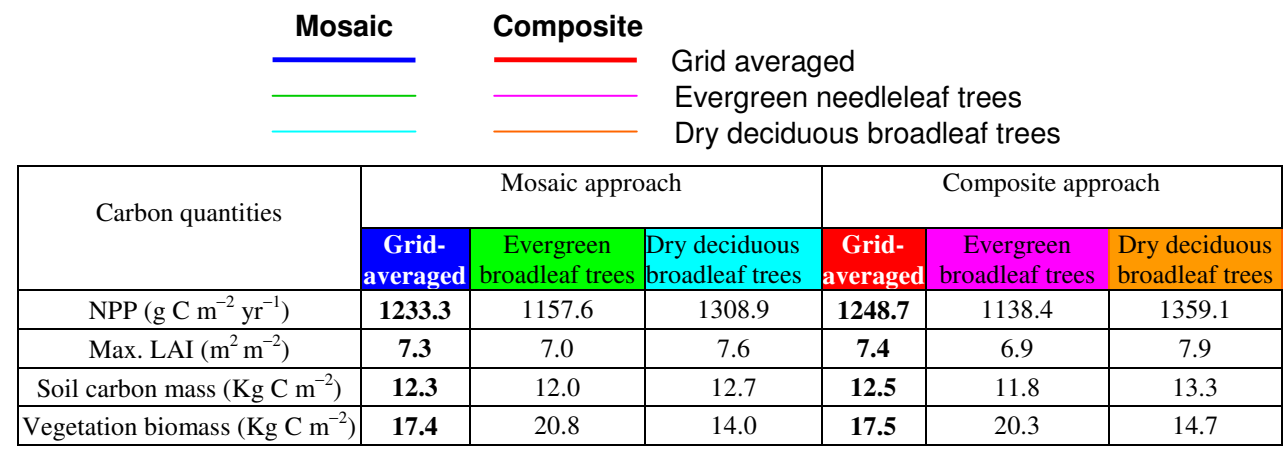

(a) $\operatorname{NPP}\left[\mathrm{g} \mathrm{C} /\left(\mathrm{m}^{2}\right.\right.$ day $\left.)\right]$

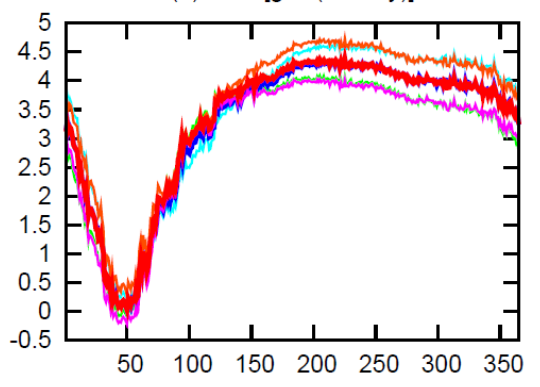

(b) $\operatorname{LAl}\left(\mathrm{m}^{2} / \mathrm{m}^{2}\right)$

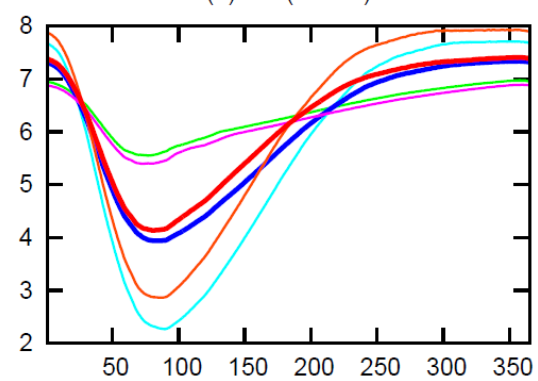

Fig. 8. Simulated daily averaged values of (a) NPP and (b) LAI for the Africa location for individual PFTs and grid-averaged values when using the two approaches. The table at the top summarizes the average annual values of NPP, vegetation biomass, soil carbon mass, and annual maximum values of LAI when using the two approaches.

The two dominant PFTs at this location (evergreen broadleaf trees and dry deciduous broadleaf trees) also have a lower difference in their albedos than the tree and grass PFTs at the boreal locations. Table 3 shows that the gridaveraged net radiation and latent and sensible heat fluxes, at this location, are virtually same in the composite and mo- saic approaches. When using the mosaic approach, net radiation flux for dry deciduous broadleaf trees is slightly lower than that for evergreen broadleaf trees because of their higher albedo (0.17) compared to that of the evergreen broadleaf trees $(0.13)$. The percentage differences in net radiation fluxes for evergreen broadleaf trees (3\%) and dry deciduous 
Table 3. Average annual values of primary energy fluxes at the Africa location when using the composite and mosaic approaches.

\begin{tabular}{lllll}
\hline \multirow{2}{*}{ Energy fluxes } & \multicolumn{3}{c}{ Mosaic approach } & Composite approach \\
\cline { 2 - 5 } & Grid averaged & Evergreen broadleaf trees & Dry deciduous broadleaf trees & Grid-averaged \\
\hline Net radiation $\left(\mathrm{W} \mathrm{m}^{-2}\right)$ & $\mathbf{1 4 4 . 7}$ & 150.1 & 139.4 & $\mathbf{1 4 5 . 1}$ \\
Latent heat flux $\left(\mathrm{W} \mathrm{m}^{-2}\right)$ & $\mathbf{7 5 . 0}$ & 74.6 & 75.4 & $\mathbf{7 4 . 4}$ \\
Sensible heat flux $\left(\mathrm{W} \mathrm{m}^{-2}\right)$ & $\mathbf{6 9 . 6}$ & 75.5 & 63.8 & $\mathbf{7 0 . 1}$ \\
\hline
\end{tabular}

Table 4. Comparison of simulated maximum annual LAI, vegetation biomass, and leaf onset and offset times with observation-based estimates for the Siberia and Eastern US locations. Simulated values are shown for both the composite and mosaic approaches.

\begin{tabular}{|c|c|c|c|}
\hline & & Siberia Needleleaf deciduous & Eastern US Broadleaf cold deciduous \\
\hline \multirow{2}{*}{ Maximum annual LAI $\left(\mathrm{m}^{2} \mathrm{~m}^{-2}\right)$} & Model & 1.8 (Mosaic) 2.2 (Composite) & 3.9 (Mosaic) 3.8 (Composite) \\
\hline & Observation based & 1-3 (Chen, 1996) & 3.5 (Schmid et al., 2003) \\
\hline \multirow{2}{*}{ Vegetation biomass $\left(\mathrm{Kg} \mathrm{C} \mathrm{m}^{-2}\right)$} & Model & 2.4 (Mosaic) 3.1 (Composite) & 7.6 (Mosaic) 7.3 (Composite) \\
\hline & Observation based & 1.95 (Kajimoto et al., 1999) & 8.11 (Schmid et al., 2003) \\
\hline \multirow{3}{*}{ Leaf onset time (day of yr) } & Model & 148 (Mosaic) 139 (Composite) & 120 (Mosaic) 120 (Composite) \\
\hline & Observation based & 143.9 (Ebata and Tateishi, 2001) & 118.8 (Ebata and Tateishi, 2001); \\
\hline & & & 120 (Schmid et al., 2003) \\
\hline \multirow{2}{*}{ Leaf offset time (day of yr) } & Model & 287 (Mosaic) 287 (Composite) & 320 (Mosaic) 320 (Composite) \\
\hline & Observation based & 290 (Ebata and Tateishi, 2001) & 320.0 (Schmid et al., 2003) \\
\hline
\end{tabular}

broadleaf trees $(4 \%)$ between the composite and mosaic approaches are small, so we also expect small differences in the carbon balance between the two approaches.

Soil temperature and liquid soil moisture content from the two approaches are compared in Fig. 7, which are averaged over the top $1.0 \mathrm{~m}$ soil layer, where most of the simulated roots for evergreen broadleaf trees $(\sim 91 \%)$ and dry deciduous broadleaf trees $(\sim 82 \%)$ are located. Grid-averaged soil moistures and soil temperatures are similar between the composite and mosaic approaches. However, compared to the composite approach, the mosaic approach yields higher (lower) simulated soil temperature and lower (higher) soil moisture for the dry deciduous broadleaf tree tile (evergreen broadleaf tree tile), especially during the dry season. Higher soil temperature and lower soil moisture for the dry deciduous broadleaf trees, in the mosaic approach, are the result of their lower LAI during the dry season when they shed their leaves (Fig. 8b).

Figure 8 shows the daily averaged values of primary carbon quantities at the Africa location. To the first order, all carbon quantities react to the differences in net radiation received and so the differences in simulated carbon balances are small. In Fig. 8b, the dry season reduction in LAI for dry deciduous broadleaf trees is much greater than that for evergreen broadleaf trees because in CTEM dry decid- uous broadleaf trees incur higher leaf loss than evergreen broadleaf trees due to soil moisture stress. Compared to the mosaic approach, NPP, LAI, vegetation and soil carbon mass are slightly lower in the composite approach for broadleaf evergreen trees and slightly higher for broadleaf dry deciduous trees. Soil moisture plays an important role at this location and determines the seasonality of NPP (Fig. 8a) and LAI (Fig. 8b).

Overall, at the Africa location, since the physical land surface environmental conditions, and in particular net radiation, are similar between the two approaches for both evergreen broadleaf and dry deciduous broadleaf trees the resulting grid-averaged carbon quantities are also similar.

\section{Discussion and summary}

CTEM has been evaluated at several individual sites by comparing simulated values of leaf onset and offset times, maximum annual LAI, root and stem biomasses and net ecosystem productivity with observation-based data (Arora and Boer, 2005; Grant et al., 2005) and at the global scale by comparing simulated net land carbon uptake for the 20th century with observation-based estimates within the framework of CanESM1 (Arora et al., 2009) in which it is coupled to CLASS using the composite approach. Table 4 shows the 
comparison of simulated maximum annual LAI, vegetation biomass, and leaf onset and offset times at the Siberia and Eastern United States locations with available observationbased estimates. Simulated values of these quantities compare reasonably well with observations for both approaches, although the mosaic approach yields a somewhat better comparison. Some limitations remain, in particular those related to the seasonality of LAI. The simulated seasonal variability of LAI for needleleaf evergreen trees at the Manitoba location is likely too large and the maximum LAI for $\mathrm{C}_{3}$ grasses and crops peaks towards the end of the growing season and not during the middle of the growing season as is generally observed. The limitations in the seasonality of simulated LAI, however, do not affect our primary conclusion that the mosaic and composite approaches of representing vegetation in a LSS yield different equilibrium states for the vegetation and soil carbon pools. We have also identified the physical and ecosystem mechanisms that lead to differences in the carbon balance between the two approaches.

Our idealized simulations, which use $50 \%$ fractional coverage for each of the two dominant PFTs in a grid cell, show that the simulated grid averaged primary energy fluxes generally do not differ by more than $5 \%$ between the two approaches at selected locations. However, the simulated carbon balance does differ between the two approaches with grid-averaged NPP, vegetation biomass and soil carbon mass differences as large as $41 \%, 16 \%$ and $46 \%$, respectively, at the locations considered. The seasonality of simulated NPP and LAI can also differ between the two approaches, as is seen at the Manitoba location. Terrestrial ecosystem processes in CTEM are sensitive to simulated physical land surface environmental conditions which in turn depend on how vegetation is represented in the LSS to which it is coupled. The differences in carbon quantities between the two approaches arise because of differences in net radiation, soil temperature, and soil moisture experienced by PFTs as well as complex interactions between environmental variables and terrestrial ecosystem processes. The dependence of different ecosystem processes on different environmental conditions can also yield unexpected results. For example, at the Siberia location compared to the mosaic approach the use of the composite approach leads to higher NPP for deciduous needleleaf trees, despite lower net radiation, because of earlier leaf onset associated with earlier availability of liquid soil moisture. This interaction with soil moisture was absent at the Manitoba location because of the evergreen phenology of needleleaf trees. Such interactions are difficult to anticipate in transient climate change simulations and cannot be accounted for in the composite approach. At the Eastern U.S. location the use of the composite approach increased all carbon quantities except vegetation biomass because $\mathrm{C}_{3}$ crops at this location were harvested and therefore did not accumulate any vegetation biomass.

The largest percentage differences in net radiation that the PFTs receive between the two approaches are simulated at the Manitoba location, followed by the Siberia, Eastern US and Africa locations. The differences in carbon balance quantities between the two approaches are also generally highest at the Manitoba location followed by other locations. These results suggest that the differences in the simulated carbon budget of PFTs between the composite and mosaic approaches arise primarily through differences in net radiation, which directly affects NPP, LAI, and vegetation biomass. Differences in net radiation subsequently also yields differences in soil moisture and temperature between the two approaches, which affect all ecosystem processes including leaf phenology and soil respiration rates, and in some cases can override the effect of differences in net radiation as was seen at the Siberia location. Is this sensitivity of CTEM to radiation realistic? The current version of CTEM does not take into account direct and diffused components of photosynthetically active radiation (PAR) separately and uses total PAR in a single-leaf approach to model photosynthesis. This is expected to increase CTEM's sensitivity to radiation. However, observation-based analysis do suggest that plant growth is limited by radiation in tropical regions with no water stress and co-limited both by radiation and temperature at high-latitudes (Nemani et al., 2003).

Whether the mosaic or composite approach offers a more realistic representation of vegetation will likely depend on the heterogeneity of the landscape (Quaife, 2010). When implemented at the global scale, terrestrial ecosystem components in ESMs are compared against observation-based estimates of vegetation, litter and soil carbon mass. The results presented here indicate that simulated carbon quantities including net ecosystem production in response to change in climate depend on how vegetation is represented in a LSS as is also found by Quaife (2010). A change in the representation of vegetation from composite to mosaic, or vice versa, will yield different environmental conditions for an ecosystem model, leading to different carbon and biological states. While we have assessed the effect of the choice of the mosaic and composite approaches on simulated carbon balance at boreal, temperate and tropical locations, these sites do not reflect the full range of possible differences. For example, it is possible that in certain transition zones the difference between the two approaches may even be larger. A full assessment of the effects of the two approaches requires simulations at the global scale and this is the focus of a future study.

\section{Supplementary material related to this article is available online at: http://www.biogeosciences.net/9/593/2012/ bg-9-593-2012-supplement.pdf.}

Acknowledgements. The authors gratefully acknowledge George Boer and Charles Curry for providing comments on an earlier version of this paper and the Canadian Regional Climate Modelling and Diagnostics (CRCMD) network. Funding was provided by the 
Canadian Foundation for Climate and Atmospheric Sciences (CFCAS) through support to the CRCMD network. We also thank the two anonymous reviewers for their helpful comments and the coordinating editor Victor Brovkin for his help and the opportunity to revise our manuscript.

Edited by: V. Brovkin

\section{References}

Arora, V. K.: Assessment of simulated water balance for continental-scale river basins in an AMIP 2 simulation, J. Geophys. Res. -Atmos., 106, 14827-14842, 2001.

Arora, V. K.: Modelling vegetation as a dynamic component in soil-vegetation-atmosphere-transfer schemes and hydrological models, Rev. Geophys., 40, 1006, doi:10.1029/2001RG000103, 2002.

Arora, V. K.: Simulating energy and carbon fluxes over winter wheat using coupled land surface and terrestrial ecosystem models, Agr. Forest Meteorol., 118, 21-47, 2003.

Arora, V. K. and Boer, G. J.: A representation of variable root distribution in dynamic vegetation models, Earth Interact., 7, 6, 2003.

Arora, V. K. and Boer, G. J.: A parameterization of leaf phenology for the terrestrial ecosystem component of climate models, Glob. Change Biol., 11, 39-59, 2005.

Arora, V. K. and Boer, G. J.: Uncertainties in the 20th century carbon budget associated with land use change, Glob. Change Biol., 16, 3327-3348, 2010.

Arora, V. K., Boer, G. J., Christian, J. R., Curry, C. L., Denman, K. L., Zahariev, K., Flato, G. M., Scinocca, J. F., Merryfield, W. J., and Lee, W. G.: The effect of terrestrial photosynthesis down regulation on the twentieth-century carbon budget simulated with the CCCma Earth System Model, J. Climate, 22, 6066-6088, 2009.

Arora, V. K., Scinocca, J. F., Boer, G. J., Christian, J. R., Denman, K. L., Flato, G. M., Kharin, V. V., Lee, W. G., and Merryfield, W. J.: Carbon emission limits required to satisfy future representative concentration pathways of greenhouse gases, Geophys. Res. Lett., 38, L05805, doi:10.1029/2010GL046270, 2011.

Brown, R., Bartlett, P., MacKay, M., and Verseghy, D.: Evaluation of snow cover in CLASS for SnowMIP, Atmos.-Ocean, 44, 223 238, 2006.

Chen, J. M.: Optically-based methods for measuring seasonal variation of leaf area index in boreal conifer stands, Agr. Forest Meteorol., 80, 135-163, 1996.

Dirmeyer, P. and Tan, L.: A multi-decadal global land-surface data set of state variables and fluxes. COLA Technical Report No. 102, Centre for Ocean-Land-Atmosphere Studies, Calverton, Maryland, USA, 43 pp., 2001.

Ebata, M. and Tateishi, R.: Phenological stage monitoring in Siberia using NOAA/AVHRR data, in: Proceedings of the ACRS 2001 - 22nd Asian Conference on Remote Sensing, 5-9 November 2001, Singapore, 412-417, 2001.

Grant, R. F., Arain, A., Arora, V., Barr, A., Black, T. A., Chen, J., Wang, S., Yuan, F., and Zhang, Y.: Intercomparison of techniques to model high temperature effects on $\mathrm{CO}_{2}$ and energy exchange in temperate and boreal coniferous forests, Ecol. Model., 188, 217-252, 2005.
Guo, L. and Gifford, R.: Soil carbon stocks and land use change: a meta analysis, Global Change Biol., 8, 345-360, 2002.

Jackson, R., Banner, J., Jobbagy, E., Pockman, W., and Wall, D.: Ecosystem carbon loss with woody plant invasion of grasslands, Nature, 418, 623-626, 2002.

Kajimoto, T., Matsuura, Y., Sofronov, M. A., Volokitina, A. V., Mori, S., Osawa, A., and Abaimov, A. P.: Above- and belowground biomass and net primary productivity of a Larix gmelinii stand near Tura, Central Siberia, Tree Physiol., 19, 815-822, 1999.

Koster, R. D. and Suarez, M. J.: A comparative-analysis of 2 land surface heterogeneity representations, J. Climate, 5, 1379-1390, 1992.

Klink, K.: Surface aggregation and subgrid-scale climate, Int. J. Climatol., 15, 1219-1240, 1995.

Leuning, R.: A critical-appraisal of a combined stomatalphotosynthesis model for C-3 plants, Plant Cell Environ., 18, 339-355, 1995.

Marsh, P., Bartlett, P., MacKay, M., Pohl, S., and Lantz, T.: Snowmelt energetics at a shrub tundra site in the western Canadian Arctic, Hydrol. Process., 10.1002/hyp.7786, 24, 36033620, 2010.

Molod, A. and Salmun, H.: A global assessment of the mosaic approach to modeling land surface heterogeneity, J. Geophys. Res.Atmos., 107, 4217, doi:10.1029/2001JD000588, 2002.

Nemani, R., Keeling, C., Hashimoto, H., Jolly, W., Piper, S., Tucker, C., Myneni, R., and Running, S.: Climate-driven increases in global terrestrial net primary production from 1982 to 1999 , Science, 300, 1560-1563, 2003.

Quaife, T. L.: Impacts of scale and heterogeneity in dynamic global vegetation models, abstract B11B-0353, presented at 2010 Fall Meeting, AGU, San Francisco, Calif., 13-17 December 2010.

Salmun, H., Molod, A., Albrecht, J., and Santos, F.: Scales of variability of surface vegetation: calculation and implications for climate models, J. Geophys. Res.-Biogeosci., 114, G02007, doi:10.1029/2008JG000762, 2009.

Schmid, H. P., Su, H. B., Vogel, C. S., and Curtis, P. S.: Ecosystematmosphere exchange of carbon dioxide over a mixed hardwood forest in Northern Lower Michigan, J. Geophys. Res.-Atmos., 108, 4417, doi:10.1029/2002JD003011, 2003.

Verseghy, D. L.: CLASS - a Canadian land surface scheme for GCMs. 1. Soil model, Int. J. Climatol., 11, 111-133, 1991.

Verseghy, D. L.: The Canadian Land Surface Scheme (CLASS): Its history and future, Atmos.-Ocean, 38, 1-13, 2000.

Verseghy, D. L.: CLASS - The Canadian Land Surface Scheme (Version 3.4) Technical Documentation (Version 1.1), Environment Canada, Climate Research Division, Science and Technology Branch, Downsview, Ontario, Canada, 2009.

Verseghy, D. L., McFarlane, N. A., and Lazare, M.: CLASS - a Canadian land surface scheme for GCMs. 2. Vegetation model and coupled runs, Int. J. Climatol., 13, 347-370, 1993.

Wang, A., Price, D. T., and Arora, V.: Estimating changes in global vegetation cover (1850-2100) for use in climate models, Global Biogeochem. Cy., 20, GB3028, doi:10.1029/2005GB002514, 2006.

Zobler, L.: A World soil file for global climate modelling, NASA Technical Memorandum 87802, NASA Goddard Institute for Space Studies, New York, USA, 1986. 